\section{FROM F2F TO ERT: UNIVERSITY STUDENTS' PERCEPTION OF REMOTE LEARNING DURING THE FIRST COVID-19 LOCKDOWN}

\begin{abstract}
In the spring of 2020, the University of South Bohemia was one of the innumerable higher education institutions which was obliged to move its instruction online in order to comply with the COVID-19 regulations. This article explores the evaluation of emergency remote teaching (ERT) measures taken by the English department from the perspective of its students. It presents and discusses findings gathered from a questionnaire completed by 99 respondents. The questionnaire centres around four areas of interest: satisfaction with ERT, comparison of face-to-face (F2F) vs. online learning experiences, perceived stress level during ERT, and acquisition of skills. The results show how students responded to the emergency procedures and which factors they considered essential in terms of satisfaction and stress. Furthermore, they reveal thought-provoking insights on aspects such as integrating elements of online teaching into F2F instruction, developing various skills in lockdown, and motivation for learning. Our findings are analysed in terms of aspects and factors which are viewed as efficient or inefficient by students in a time of crisis. Thus, this research may contribute not only to better preparedness should circumstances requiring ERT return, but also to a more complex re-evaluation of instructional approach at university level.
\end{abstract}

\section{KEYWORDS}

ERT (emergency remote teaching), F2F (face-to-face) instruction, online learning, student satisfaction, university education

\section{HOW TO CITE}

Dvořáková K., Emmer J., Janktová R., Klementová K. (2021) 'From F2F to ERT: University Students' Perception of Remote Learning During the First COVID-19 Lockdown', Journal on Efficiency and Responsibility in Education and Science, vol. 14, no. 2, pp. 89-100. http:// dx.doi.org/10.7160/eriesj.2021.140203

\section{Kateřina Dvořáková \\ Jaroslav Emmer \\ Renata Janktová \\ Kateřina Klementová}

University of South Bohemia in Ceske

Budejovice, Czech Republic

katerina@pf.jcu.cz

\section{Article history}

Received

September 11, 2020

Received in revised form

March 5, 2021

Accepted

April 14, 2021

Available on-line

June 30, 2021

Highlights

- Comparison of face-to-face and emergency remote teaching in terms of student satisfaction and stress.

- Opportunities for interaction with teachers and classmates, class discussions, and mutual feedback were the face-to-face educational aspects most lacked by students in emergency remote teaching.

- Emergency remote teaching promoted the acquisition of various skills among students.

- Tolerance and solidarity among students and teachers in a time of crisis.

\section{INTRODUCTION}

Three weeks into the 2020 spring semester, Czech higher education institutions were confronted with an unprecedented challenge - to shift from face-to-face (F2F) to (emergency) remote teaching practically overnight. The government lockdown that was put into effect disrupted the usual routines but did not relieve most citizens of their job or study-related responsibilities. Educators were expected to continue delivering lessons, holding consultations, and carrying out assessment, while the students" "end of the bargain" was not to miss out on assignments, complete the semester on time, and most importantly, not to compromise the efficiency of their schoolwork.

The abrupt pivot from classroom to remote teaching held up a mirror to the long-standing practice of distance education. Noffsinger's (1926) thorough research into distance education outlines a systematic description of American correspondence study (Black, 2019), and highlights that it began as early as the 1840 s. The decades that followed saw degrees being awarded for distance learning and college classes televised on public 
channels (OnlineSchools.org, 2020). During the 1970s and 80s, the equality of distance and F2F education was still regarded as 'a preposterous idea' (Moore, 2019: 32), but in the late 20th century the various forms of distance education were fully exploited. Since then, courses now known as online learning, e-learning, or blended learning, have been gaining momentum. According to Leonnard (2019), university students' loyalty to their institution is significantly influenced by their satisfaction with the quality and efficiency of their online sites and platforms. Work of organizations such as Coursera (founded in 2012), which brings courses from top universities online for free and aims to reach millions of prospective students worldwide (Koller, 2012), only justifies the publication by The Ministry of Education, Youth and Sports (MEYS, MŠMT), which claims that most universities already work with an array of online tools, which makes them highly experienced in providing online education. That being said, regarding the COVID-19 related measures in higher education, MEYS warns that in the event of a sudden shift from F2F to distance learning, the approach to the system of education would require revision. Moreover, related processes such as communication, planning, and selection of appropriate methods and tools, need to be provided (MŠMT, 2020).

MEYS's appeal corresponds with Hodges et al. (2020), who differentiate between planned online learning and courses taught online in response to a crisis or disaster. To identify the latter, they suggest the term emergency remote teaching (ERT). This refers to the specific type of instruction delivered in crisis circumstances and has become an alternative term used by education researchers and practitioners in order to disambiguate it from quality and well-designed online education. ERT represents a temporary alteration of instructional delivery mode. It involves the use of remote teaching solutions that would otherwise be provided F2F and that will be restored when the emergency tapers off. Its central objective is to provide provisional and easily accessible instruction during an emergency or crisis. Bozkurt and Sharma (2020) emphasise that unlike distance courses, which are an optional form of education, emergency remote teaching is an obligation. Therefore, its educational content might be overshadowed by what students remember in terms of feelings during the difficult times. Hodges et al. (2020) further accentuate that the limited time available for the establishment of ERT may affect the quality of the courses (in a planned situation such courses frequently take months to be developed). Referring to the CIPP Evaluation Model by Stufflebeam and Zhang (2017), they propose that 'the urgency of ERT and all that will take to make it happen in a short time frame will be the most critical elements to evaluate during this crisis' (Hodges et al., 2020). They also add that the evaluation of institutions' ERT efforts should focus more on the context, input, and process aspects rather than the product itself (i.e. learning and whether or not or to what extent it occurred).

In search of an evaluation of our ERT efforts, the English department members created a questionnaire focusing on four major areas which proved to be the most discussed aspects of the stance taken towards ERT by both the students and the teachers throughout the ERT-defined semester. We inquired how satisfied the students were with the ERT mode for reasons we managed to collect in further sets of questions. These questions encouraged the respondents to comment on the comparison of face-to-face (F2F) vs. online learning experiences, perceived stress level during ERT, and acquisition of skills. The first Covid-19 lockdown in the Czech Republic saw acts of solidarity on countless fronts with education being one of them. Compelled by the sense of responsibility for the efficiency of our effort, we designed the survey to collect feedback on the department's application of ERT during the lockdown, and at the same time to offer the students a safe space to share their immediate reflections of their own role and participation in the unprecedented situation.

\section{THEORETICAL BACKGROUND}

\section{Face-to-face vs. online experience}

Regardless of the form of learning (F2F or online), its effectiveness is always supported by social interaction, i.e. instructor presence. Traditional F2F learning allows more student-teacher and/or student-student interaction than the online learning environment (where all parties are forced to use technology as a tool for interaction). Additionally, online interaction is often reduced to text (Ramsden, 2003). There are, however, features of online interaction that students perceive as essential indicators of the much sought-after instructor presence. These include comprehensible course requirements, prompt response to students' demands, and provision of timely feedback (Sheridan and Kelly, 2010). Minimal peer communication has an adverse impact on motivation and feelings of isolation (Hartnett, 2015). Therefore, instructors ought to establish and maintain online presence (Hartnett, 2019) and foster online learning communities by encouraging group discussions and peer interaction (Vayre and Vonthron, 2019).

An investigation into the expectations about the roles of students and teachers in online courses conducted by Bork and Rucks-Ahidiana (2013: 21) shows how important both the voice and eye contact between students and teachers is in helping them 'to feel a sense of connection to the instructor and the course'. The same research suggests that students' feeling of being taught actively stems from relevant, tailor-made course materials. The findings of Cleveland-Innes, Garrison and Vaughan (2019) indicate that social presence in online learning, i.e. in the environment of inquiry and shared purpose, contributes to discourse, enhanced productivity and learning outcomes.

The online pedagogy guide published by Harvard University (2020) mentions that within online learning, technologies can provide a more "lean forward" atmosphere and urges teachers to exploit this fact. Inasmuch as today's students are considered to be digital natives, it is advisable to present traditionally "lecture-based" courses remotely, i.e. online (Harvard University, 2020).

Conversely, there are critical voices that warn against a rapid spread of online learning. Their main concern is with the maintenance of quality of higher education. These critics also call attention to clinical work or fieldwork, which are difficult to 
conduct with online tools. They emphasise the value of college experience outside of the curriculum - which is virtually nonexistent in the online world (Shapiro et al., 2017).

At the same time, the proverbial digital native status of today's students has yet to be proved under university online learning circumstances. There is the technical aspect of studying and working online, which seems to be less of a problem for most students. However, critical thinking, giving unequivocal statements, organizing thoughts and ideas, and cooperation are among those skills which online students do not possess (Parkes, Stein and Reading, 2014).

\section{Satisfaction with online education}

When expressing satisfaction or dissatisfaction with online learning, students tend to focus their assessment on the role and performance of the teacher. Bolliger and Martindale (2004) argue that the instructor is the chief predictor in student satisfaction, and they list several features of a teacher's performance that correlate with student satisfaction. These include the teacher's accessibility, flexibility, organizational skills, and the ability to be inspiring, encouraging and motivating. Students expect encouragement to make them active participants in the online learning process.

The psychology-grounded self-determination theory (SDT; Ryan and Deci, 2017) assumes that pupils and students are intrinsically motivated to learn and thrive academically. This intrinsic drive is accompanied by the psychological needs of achieving autonomy and a feeling of social belonging. Achievement-oriented motivation is at the centre of goal orientation and performance orientation theories. In relation to distance education, learning goal orientation has been found to enhance student participation in online discussions as well as overall course satisfaction (Hartnett, 2019).

Jindrová, Vostrá Vydrová and Dömeová's (2013) survey of students' satisfaction with e-learning courses gives evidence that low levels of students' self-discipline along with lack of motivation to do schoolwork correlate with high demand for e-support including swift feedback from teachers. The survey results also show that unmotivated students perceive the teachers as less qualified and they are critical of the overall quality of the course.

To perceive the online learning process as successful, students require systematic monitoring of their progress (Bolliger and Martindale, 2004). The instructor's feedback is a source of validation and confirmation of both the students' work and their identity. Students in online courses need identity validation, because limited opportunities to develop relationships can lead to feelings of isolation and invisibility. Online communication is often perceived as less personal, i.e. dissatisfying, thus creating a socializing interaction proves to be essential for student satisfaction (Allen et al., 2019).

The lack of teacher social presence and immediate feedback can trigger computer-mediated communication anxiety (CMCA), which can, conversely, influence learners' perceptions of instructor credibility, online teaching presence, and learning outcomes (Wombacher et al., 2017). Additionally, students expect to be informed on their progress and 'they like to contextualize what they are learning by applying the information in real life' (Ally, 2008: 29). Practice activities simulating real-life situations, which are included in online learning materials, determine relevance and perceived value of these materials. Feedback, which the practice activities provide, helps students to review their learning method and make appropriate corrections (Ally, 2008).

Further, teacher's positive and open approach to the IT aspect of online learning influences the students' results and subsequently their satisfaction. However, what contributes to student satisfaction most significantly are features of online education such as well-prepared teaching materials, suitable online discussion arrangements, course design, scheduling and instructional expertise (Sun et al., 2008). Kuo et al. (2013) also list learner-instructor interaction, learner-content interaction, and Internet self-efficacy as credible indicators of student satisfaction.

\section{Online vs. face-to-face: stress, anxiety, frustration}

Several studies (e.g. Saadé and Kira, 2009; Sun, 2014; Shapiro et al., 2017) suggest that approximately one third of learners experience some level of anxiety or unease in relation to online learning or perceive their learning during an online course as less effective compared to the traditional classroom model (Muilenburg and Berge, 2005; Wombacher et al., 2017). While low levels of stress or anxiety may stimulate motivation and performance, high levels have a negative impact on motivation, engagement levels and academic achievement (Heckel and Ringeisen, 2019).

High task assessment weight in relation to the overall course mark is a major stressor and inhibitor in online courses (Hartnett, 2015). Korpi (2019) argues that stress and frustration caused by high-stake assessment can be significantly reduced by multiple, low-stake iterative assessment and targeted feedback. Iterative assessment and instructor feedback review increase student engagement and enhance the capability of self-reflection.

Misalignment of student and instructor expectations and the consequent role ambiguity are other potential sources of tension and frustration (Bork and Rucks-Ahidiana, 2013). The absence of the usual socialization process that occurs in the traditional classroom requires respective role shifts; instructors must also become learning and communication facilitators, whilst learners must increase their own activity in acquiring knowledge (ibid.) and accept greater responsibility for the learning process and outcome. Following Bork and RucksAhidiana's survey (2013), the main areas where instructor expectations about online students are misaligned with the students' perceptions and expectations are technological preparedness, learning management skills, and help-seeking behaviour. For example, while instructors expect intrinsic motivation and self-regulation, students expect to be encouraged and motivated by instructors and to receive more guidance with task and content prioritization and complying with coursework requirements. Student expectations reported as mismatched concerned instructor communication habits, substantive feedback and online presence and pedagogy.

According to Vayre and Vonthron (2019), the lack of instructor 
presence, interaction and immediate feedback as well as the insufficient interaction with the class may lead to feelings of disconnection and frustration, and eventually to failures. Their study demonstrates that the feeling of community, belonging and connectedness has a positive impact on academic selfefficacy, which is a major factor in student engagement and success in online courses. Students with higher online learning self-efficacy feel that they are in greater control of the learning process and experience lower levels of anxiety and higher levels of pride (Heckel and Ringeisen, 2019). On the other hand, low levels of anxiety correlate with higher course satisfaction.

Online learning self-efficacy, associated with the use of ICT technologies and learning management systems (LMS), depends on computer self-efficacy and previous online learning experience (Saadé et al., 2017). A survey performed by Saadé et al. (2017) showed that approximately $30 \%$ of students feel some sort of anxiety in respect to online courses. Saadé and Kira (2009) argue that technology-related anxiety has a negative influence on the perceived ease of use of LMS, academic self-confidence, general stress and anxiety levels, and, consequently, the overall course performance and satisfaction. The occurrence of computer anxiety is linked to the growing value of e-learning as well as the continuously rising complexity and integration of interfaces. Other potential technology-related obstacles in online learning include asynchronous communication (Hartnett, 2019), becoming easily distracted, and difficulties in managing the great amount of information available online (Newman and Beetham, 2017). Many of the potential stressors and anxiety triggers recognized in scheduled online teaching apply to emergency remote teaching (ERT). They include the loss of both teacher and student social presence, disruption of synchronicity, and instability of expectations (Whittle et al., 2020). Student stress and anxiety can be prevented or alleviated by a proactive instructor approach which is centred on clarity of instruction and communication, considerate workload control, as well as flexible, lower-stake assessment (Quintana and Quintana, 2020).

Most participants in a large-scale survey in China reported that the continuation of classes online had helped them manage mental stress caused by the COVID-19 quarantine (Sun, Tang, and Zuo, 2020). In response to the current pandemic experience, Gross (2020) argues that the online learning environment can, and ought to be, trauma-responsive and help students and staff deal with anxiety or traumatic states provoked by health concerns, school closures, social and emotional isolation, etc. Suggested strategies that can promote student engagement and success include facilitating personal interaction, making the visual message in video meetings interesting and encouraging, including engaging "non-academic" exercises, and trying new approaches and methods enabled by online settings.

\section{Motivation and skills development}

Student motivation is one of the most significant factors that influence academic achievement. It determines students' choices and actions and is thus responsible for the level of engagement in educational activities (Wentzel and Brophy, 2014). According to the expectancy-value theory (EVT; Eccles and Wigfield, 2002), motivation is primarily sustained by the belief in one's competence and expectancy for success, and the perception of value and relative costs in relation to specific tasks. The perceived value of tasks depends most notably on their attainment and utility values in relation to students' interests and goals (Jindrová, Vostrá Vydrová and Dömeová, 2013; Hartnett, 2019).

Interest theories (Schiefele, 1991, 1999; Hidi and Harackiewicz, 2000) distinguish between individual and situational interests. While individual interest is viewed as a relatively stable aspect of personal characteristic, situational interest is generated by environmental factors that attract students' attention to specific learning contents and activities. Situational interest appears particularly beneficial in students with low levels of academic motivation (Hidi and Harackiewicz, 2000). Hidi and Renninger (2006) conceptualize interest development as a fourphase process by differentiating emerging and well-developed individual interests and triggered and maintained situational interests. Triggered situational interest, generated through novelty or originality, is the temporary first phase that can develop into maintained situational interest. These two stages are pre-conditions of emerging and, eventually, well-developed individual interests.

The belief of students in their ability to perform adequately in educational contexts is at the centre of the self-efficacy theories. Self-efficacy is ranked among the key factors that influence learning behaviour and academic achievement (Schunk, 1989) and has been used as a predictor of students' motivation and learning (Zimmerman, 2000). The levels of self-efficacy are determined, among other things, by appropriate goal setting and instruction, as well as the provision of attributional and performance feedback. Students with high self-efficacy are less prone to experience frustration, stress and anxiety (Schunk, 1989). They also demonstrate strong self-regulatory abilities such as goal setting, self-monitoring, and self-evaluation (Zimmerman, 2000).

Student motivation is a key factor that affects learner persistence and success in online education (Hartnett, 2015). In Muilenburg and Berge's survey (2005), learner motivation is reported to be the second most urgent barrier to online learning. As mentioned above, not all students are able to gain from the benefits of asynchronous learning, such as spatial and temporal flexibility (also Hartnett, 2015; Vanslambrouck et al., 2018). A mixed SDT \& EVT-based study by Vanslambrouck et al. (2018) suggests that on its own the online environment has a fairly low impact on intrinsic and attainment values. This means that the online form itself does not significantly increase personal enjoyment and boost self-esteem. On the other hand, the utility value, i.e. the practical benefits and outcomes in relation to particular goals and ambitions appears to be the main asset. This includes not only reaching educational goals but also developing additional skills such as IT competencies, time management, and selfregulated work. Sun's survey (2014) revealed that students appreciated improvements in independent learning strategies, such as planning and monitoring course activities and seeking feedback when necessary. They also reported progress in their real-life problem-solving skills. 
Considering that peer interaction restrictions are perceived as a major barrier to online learning, it is interesting to see that e-learning can also enhance certain social skills. Specifically, teaming up online and collaboration in small groups prove fruitful as they foster new communication and interaction skills (Sun, 2014). Self-regulated online learning also provides opportunities for developing self-assessment and critical reflection skills (Conrad and Openo, 2018). Clear, structured support, including cognitive scaffolding and balanced teacher presence, is, nevertheless, necessary in order to prevent feelings of uncertainty and frustration (Stavredes and Herder, 2019). Bork and Rucks-Ahidiana's study (2013) confirms that while most students accept greater responsibility when learning online compared to classroom settings, they expect instructor guidance and help. It also suggests that students who take responsibility for their learning are more proactive in terms of reflection, self-evaluation, and seeking feedback. Effective self-assessment tools include reflective records, such as logs or journals, or feedback essays and questionnaires (Conrad and Openo, 2018). The costs, i.e. negative aspects of distance learning, include excessive workload and technological issues, particularly computer skills and ICT equipment. Online interaction and organizing group work are also experienced as problematic by some students (Vanslambrouck et al., 2018). Nonetheless, most surveys reviewed in this paper present online learning, including the recent ERT cases, as a generally positive experience.

\section{MATERIALS AND METHODS}

The presented research is an ex-post facto case study which aims to examine university students' experiences and perceptions related to the sudden shift from F2F to ERT mode of instruction during the first COVID-19 lockdown. Hypotheses are not proposed within this research design as it focuses on the examination and description of previously unexplored phenomena brought about by the consequences of the COVID-19 pandemic in tertiary education. The research questions were formulated on the basis of observations and concerns collected by the faculty. Several hypotheses which emerged as a result of our findings will be suggested in the discussion section as possibilities for further research and investigation.

The research was carried out at the University of South Bohemia, a medium-sized Czech public university, one of the numerous educational institutions worldwide that was obliged to cancel all F2F classes for ten weeks (March - May 2020) in response to the COVID-19 restrictions and resort to ERT to maintain the continuity of instruction. Although none of the members of the English department of the Faculty of Education had actively created or conducted online courses, without firm guidelines each instructor employed traditional as well as modern electronic tools to deliver the content, but most importantly to assure the students that the semester continues with active participation of all stakeholders. The feeling of being under an undefined obligation was prevalent in the first weeks of the lockdown. At home and at school, most students found themselves expecting clear directions "from day one", but instead they had to learn to adapt to change.
The unprecedented teaching experience prompted the department members to conduct an evaluation of its ERT efforts. Their interests centred around the students' attitudes, perceptions, and experiences with the contingency measures applied in their English language study programme and induced the following input and process-related evaluation questions:

1. What factors affected university students' satisfaction or dissatisfaction with ERT?

2. How did the ERT experience compare with face-to-face learning?

3. How stressful for university students was ERT compared with face-to-face learning?

4. Did the ERT situation impact the students' acquisition of language and other skills?

A questionnaire entitled Students of English reflecting on their emergency remote teaching was created by the English department and distributed among all its students immediately after ERT termination at the end of May 2020. It was introduced by a personal letter from the head of the department explaining its constructive purpose in improving the quality of the department's work. Students were also informed of the confidential nature of the questionnaire. The main aim of the questionnaire was to collect information on and evaluate how students perceived the unparalleled academic experience, namely in terms of their satisfaction or dissatisfaction with various aspects of online learning as implemented by the English department in the spring semester of 2020 in response to the COVID-19 pandemic situation (input evaluation). The motivation to inquire about satisfaction stemmed from the provisional nature of ERT, which, as we gathered from students' indications during less formal parts of lessons or during consultations, was perceived both positively and negatively. In addition, it explored three further process evaluation issues: the differences they experienced by having to learn online as opposed to F2F instruction, the stress level the students underwent, and the skills they acquired during the three months of involuntary and unplanned distance learning.

The questionnaire consisted of fifteen questions. The first two questions identified the students' status (degree programme and year of study). Five questions were closed and required respondents to provide answers on a scale or select from given options. Four questions were open, inviting the respondents to express themselves at liberty and make personal comments related to the areas of interest (see Table 1 below).

The remaining four questions included in the questionnaire provided feedback related to specific subjects at the department and were not included in our analysis.

A total of 99 respondents, 68 Bachelor's and 31 Master's degree students training to become primary or lowersecondary English foreign language teachers, voluntarily completed the online, anonymous questionnaire using Microsoft Forms.

The main limitations of our study are its narrow and heterogeneous sample of respondents and the feedbackdriven formulation of questions, which make the use of statistical validation methods inapplicable or irrelevant. 


\begin{tabular}{|c|c|c|}
\hline & $\begin{array}{l}\text { CLOSED QUESTIONS } \\
\text { scale/options }\end{array}$ & OPEN QUESTIONS \\
\hline \multirow{2}{*}{ SATISFACTION } & $\begin{array}{l}\text { How satisfied were you with ERT instruction at the English } \\
\text { department? }\end{array}$ & \multirow[t]{2}{*}{$\begin{array}{l}\text { What were your reasons for feeling satisfaction } \\
\text { and/or dissatisfaction? }\end{array}$} \\
\hline & $\begin{array}{l}1=\text { dissatisfied } 2=\text { fairly satisfied } 3=\text { satisfied } 4=\text { very satisfied } \\
5=\text { fully satisfied }\end{array}$ & \\
\hline \multirow[b]{2}{*}{ F2F VS. ONLINE } & Which aspects of F2F instruction did you lack during ERT? & \multirow{2}{*}{$\begin{array}{l}\text { Explain which aspects of your ERT experience you } \\
\text { consider suitable or unsuitable for potentially } \\
\text { incorporating into F } 2 F \text { instruction. }\end{array}$} \\
\hline & $\begin{array}{l}\text { contact with instructors, contact with peers, mutual discussion, } \\
\text { feedback from instructors and peers, comparison with others }\end{array}$ & \\
\hline \multirow{2}{*}{ STRESS LEVEL } & How stressful did you find ERT in comparison with F2F? & \multirow[t]{2}{*}{ What did you find stressful during the ERT period? } \\
\hline & absolutely not - partly - equally - more - significantly more & \\
\hline \multirow{4}{*}{$\begin{array}{c}\text { SKILLS } \\
\text { DEVELOPMENT }\end{array}$} & How did your English language skills change during ERT? & \multirow{4}{*}{$\begin{array}{l}\text { Did you acquire any other skills not necessarily } \\
\text { related to your field of study? }\end{array}$} \\
\hline & improved - did not change - became worse & \\
\hline & $\begin{array}{l}\text { Which activities did you undertake to develop your language } \\
\text { skills over the ERT period? }\end{array}$ & \\
\hline & $\begin{array}{l}\text { listening to the news, watching TV, watching films and shows, } \\
\text { playing video games, chatting with friends, reading newspapers } \\
\text { or online articles, reading books, other }\end{array}$ & \\
\hline
\end{tabular}

\section{RESULTS \\ Satisfaction}

Respondents indicated the degree of their satisfaction with ERT on a scale from 1 (substandard) to 5 (excellent). The average overall score was 4.07 (4.11 in the BA and 3.97 in the MA programme). In their comments, they specified their answers and the most reported reasons for satisfaction were:

- quality of communication and proactive approach of the instructor

- regularity, clarity and good organization of instruction

- adequate number of assignments, sufficient time for their completion, reasonable adjustment of requirements when necessary

- prompt response from the instructor and the provision of quality feedback.

Numerous students noticed and appreciated that some instructors were extremely flexible and capable of reorganizing their courses quickly to accommodate to the new conditions and limitations. They carried on with class work and enabled regular online communication and consultations. Moreover, they were willing to make certain concessions regarding assignments and testing and announced their deadlines and test/exam dates well in advance. In certain subjects, students even felt that "instruction was close to what it is like in regular lessons." Regular assignments considerably helped certain students with their time management in the emergency period and boosted their morale. One respondent appreciated that she was even able to complete her teaching practice during the ERT by participating in the elementary school's ERT.

A certain degree of dissatisfaction related to a specific subject and its instructor was expressed by one third of respondents. Open answers revealed that the main factors for dissatisfaction included unclear instructions and absence of prompt or sufficient feedback. Although the students understood the emergency circumstances and generally tried to adapt to them, they described certain measures such as limited or no interaction with peers as inevitable but dissatisfactory. Students were also critical of the occasions when online instruction started much later than expected, or when there were only weekly tasks and/or assignments but no actual online instruction. Only one respondent's explanation was linked to their fear of passing a test.

\section{Face-to-face vs. online}

Respondents were asked to rate to what extent they lacked five aspects of F2F education in their ERT. Figure 1 reveals that the answers were very similar in terms of contact with faculty members, contact with fellow students, participating in discussions, and receiving immediate feedback from instructors and fellow students. More than $80 \%$ of students stated that during ERT they significantly or partly missed opportunities for interaction with teachers and classmates, class discussions, and mutual feedback. On the other hand, the one aspect that was missed by only $14 \%$ of students was comparing with others. The majority of students (61.6\%) did not miss comparing with others at all and $24.2 \%$ lacked comparing with others partly during distance teaching.

F2F education aspects lacked in ERT

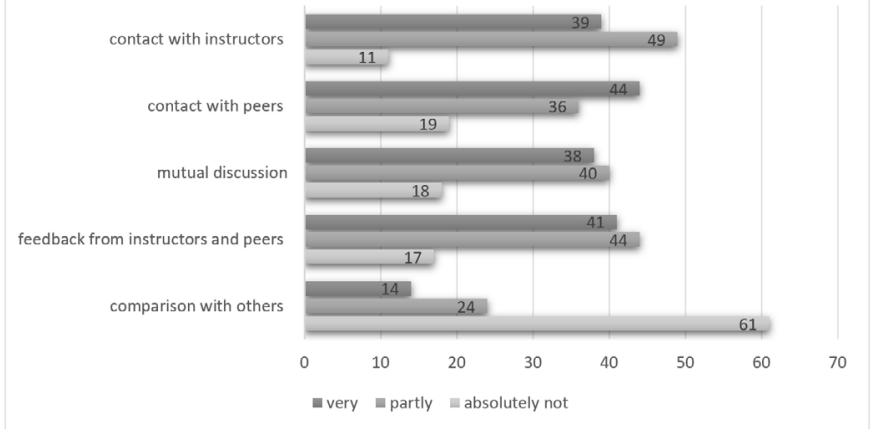

Figure 1: F2F education aspects lacked in ERT.

Additionally, respondents could explain which aspects of online instruction they considered most and least convenient and/or which aspects could or should not be incorporated into 
the study programme. Online instruction was found to be more effective in terms of time management by thirteen respondents as "time is not wasted by travel" and "more time can be devoted to the completion of assignments". Twenty-four suggested that in certain courses, namely the more theoretically based ones such as literature or history, lectures could be delivered online even when the situation returns to normal. Seven indicated that the online lectures during ERT were surprisingly interesting and practical in that students could listen to them repeatedly and devote more time to fully grasping the content. Four respondents maintained that online instruction was generally unsuitable for foreign languages and the same number believed that most subjects in a foreign language programme could to a certain extent be taught online. Three students stated that studying online encouraged them to do more research and further reading. On the contrary, online teaching was labelled as completely or largely unsuited to the teaching of speaking skills and/or pronunciation by more than half of the respondents, even though one also admitted that "where there is a will, there is a way." Also, fourteen respondents recognized linguistics and phonetics as inappropriate for online instruction - as these skills are considered highly demanding and require thorough in-class discussion.

\section{Stress level}

Figure 2 shows that almost two thirds of the participants found ERT absolutely or quite acceptable, about one fifth considered it to be equally stressful as F2F teaching, and one fifth viewed it more or much more stressful than F2F classroom interaction.

Further comments revealed that in terms of stress level, a number of respondents appreciated learning at their own pace, at their preferred time of the day, often in the comfort of their homes ("you can wear your pyjamas, lie on your bed, eat or drink, and no one minds"), which was regarded as less stressful than working at school. As one respondent put it, "I generally found learning online positive. One can fully focus without being disrupted by the surroundings." Students also reported that they were able to concentrate better on the content of lectures delivered online or posted as videos because in the F2F format lectures "sometimes tend to be very noisy with classrooms full of students."

On the other hand, some students perceived the use of different communication platforms by different instructors across the courses as extremely chaotic and stressful. One student also suggested that "there should be clear guidelines for similar situations."

As the respondents were both BA and MA students, one of the objectives was to test if the degree programme impacts the perceived stressfulness. The chi-square test was used to test the null hypothesis, i.e. there is no significant difference between BA and MA students in their evaluation of stressfulness. See Table 2 for the gathered data - the brackets contain the expected frequency.

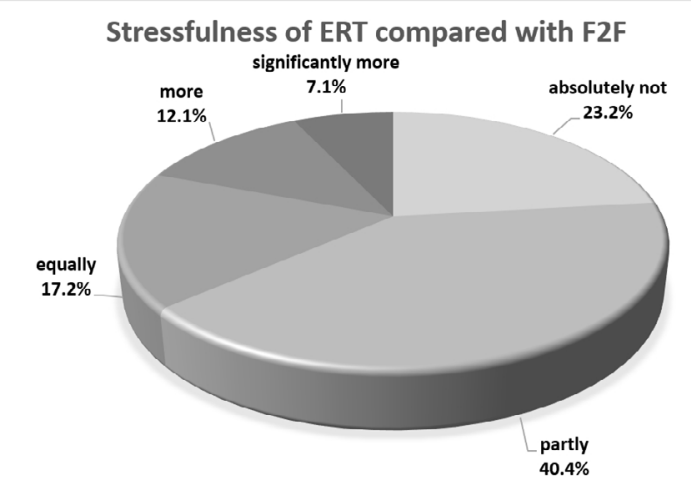

Figure 2: Stressfulness of ERT compared with F2F.

\begin{tabular}{lcc|c|c|ccc} 
& absolutely not & partly & equally & more & significantly more & total \\
\hline BA & $18(15.8)$ & $24(27.5)$ & $10(11.7)$ & $11(8.2)$ & $5(4.8)$ & 68 \\
\hline MA & $5(7.2)$ & $16(12.5)$ & $7(5.3)$ & $1(3.8)$ & $2(2.2)$ & 31 \\
\hline total & 23 & 40 & 17 & 12 & 7 & 99 \\
\hline
\end{tabular}

Table 2: Stressfulness of ERT compared with F2F - BA vs. MA students

The chi-square test shows that the degree programme is, indeed, statistically not significant for the stress level evaluation $\left(x^{2}=6.26, d f=4, p=0.1819\right)$.

\section{Skills development}

The participants were asked to subjectively assess whether their English language skills had changed over the three-month ERT period. 68 did not report any significant difference in their language skills, 24 noticed improvement, and 7 felt that their language skills had deteriorated.

All respondents made some effort to improve their language skills in their leisure time. The most popular activities were watching films and TV series (93), reading newspapers and online articles (58), and reading books (55). They also engaged in communicating with friends in English (38), listening to the news (25), playing video games (23), and watching television (see Figure 3). In the open answers, six respondents reported 
that they had been able to explore their topics in greater depth or that their school assignments submitted during online learning had been of much higher quality than during regular classes as they had more time for their completion. Two highlighted the new opportunity to devote time to developing the language skills of their choice.

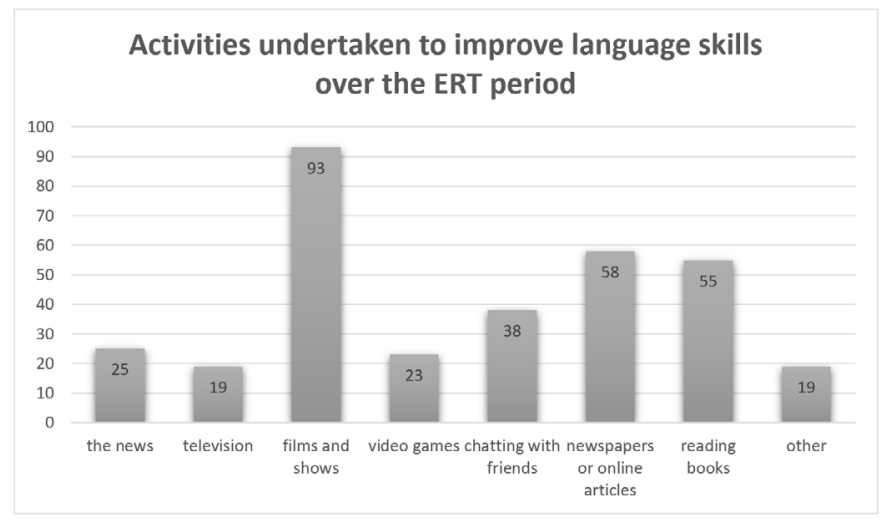

Figure 3: Activities undertaken to improve language skills over the ERT period.
Other reported ways of enhancing respondents' foreign language skills included reading specialized/scientific books, tutoring, vocabulary practice using the Duolingo app, listening to podcasts, and translating. The open answers revealed that the emergency also positively influenced the students' acquisition of other skills, namely:

1. gaining more competence, confidence, and flexibility in the use of technologies (25 respondents)

2. improving time management and organizational skills (25 respondents)

3. becoming more independent and autonomous ( 23 respondents)

4. becoming more effective in working with various resources and/or specialized literature (11 respondents)

5. gaining new teaching skills (2 respondents)

6. learning a new language (1 respondent)

Only 11 respondents indicated that they had not developed or improved in any other skills or did not know how to answer the question.

The comparison of BA and MA students in Table 3 indicates that the acquisition of technological skills was reported by more than a third of all the MA students (38.7\%). We will return to the potential explanation of this phenomenon in the discussion.

\begin{tabular}{lcc|c} 
& technological skills & time management & independence \\
\hline BA & $13(19.1 \%)$ & $19(27.9 \%)$ & $15(22.1 \%)$ \\
\hline MA & $12(38.7 \%)$ & $6(19.4 \%)$ & $8(25.8 \%)$ \\
\hline total & $25(25.3 \%)$ & $25(25.3 \%)$ & $23(23.2 \%)$ \\
\hline
\end{tabular}

Table 3: Skill acquisition during ERT - BA vs. MA

\section{DISCUSSION}

As mentioned earlier in this paper, the current generation of students are generally regarded as digital natives not only by the instructors, but also by themselves. The ERT pivot put this assumption to the test and the responses available show that $25.3 \%$ of the students believe to have improved their IT skills over the duration of ERT. It follows from this finding that online teaching, regardless of the course content, has the potential to further develop overall digital competence, which is gradually becoming an integral part of our skillset. The implication is that we need to be careful when making generalisations about students' digital skills, because many of them may not be as well equipped for online learning as we would like to believe. This finding correlates with Bork and Ruck-Ahidiana's (2013) identification of technological competence as one of the main points of misalignment between students' and teachers' assumptions and expectations in online education. The logical course of action is to implement more IT-based tasks into standard teaching and provide necessary support in the form of further training in technological competence.

Since the digital environment suddenly became the main hub, the responsibilities of students in this new setting became less clear - this may lead to higher levels of anxiety. Consequently, students had to re-evaluate their role during the pivot, and their responses showed that they sought guidance in the form of instruction, timely and relevant feedback, and encouragement. The instructors had been expected to take on greater responsibility for facilitating discussion and involvement of the students. One of the respondents reported that the lack of online (real-time) seminars in a particular subject resulted in the instructor having "not enough leverage to make students work if they do not want to." Other respondents mentioned in their comments that they had been waiting for the instructors to find a way to engage them due to the lack of guidelines for such a situation. As Lehman and Conceicao (2010: 28) explain, instructors become designers of the online experience for students. The formal position of authority of the instructor remains, but there is also a new role of moderator in the online environment, which is crucial for the online learning to be successful (cf. Sun, 2011, 2014; Martin, Wang and Sadaf, 2018; Stavredes and Herder, 2019).

The ability of the instructor to adapt to this shift of responsibility from student to teacher was another key factor in determining the overall satisfaction with ERT. Conversely, the lack of doing so reportedly resulted in dissatisfaction and additional stress as the students were left to determine their responsibilities on their own. In our questionnaire, five students reported frustration with different instructors using various platforms and/or not providing clear instruction related to course completion. While it is understandable that each instructor might prefer working with a certain platform based on their previous experience, the inconsistency remains a negative factor in ERT and should be subjected to revision (cf. Sun, 2011). Additionally, we believe that providing clear instructions is essential for any non-standard mode of education and the students need to receive these instructions promptly.

Next, we would like to comment on $61.6 \%$ of the students not missing the comparison with others. This was one of the seemingly surprising findings that has important implications - 
especially for teachers who use relative grading (also referred to as marking on the curve, grading on a curve, bell curving, etc.). While social interaction among students is widely regarded as indispensable for effective education (e.g. Hurst, 2013; Sun, 2011) and the comparison to others is likely to occur individually, it may become an inhibiting factor in F2F education due to its stress potential (cf. Buunk and Gibbons, 2005; White et al., 2006; Civitci and Civitci, 2015). There seem to be limited benefits to using comparison with others as our results suggest that students do not respond well to such form of encouragement (cf. Civitci and Civitci, 2015).

As much as ERT is essentially a contingency measure and most of the students would still prefer F2F education, $25.3 \%$ of the students mentioned in their responses the flexibility of time management and work organisation as a beneficial aspect of ERT. While there were several scheduled online classes that the students were expected to attend, they welcomed the possibility of recording the online sessions and the opportunity to return to them at their own convenience. $10.1 \%$ of the students explicitly stated that they would prefer lectures to be carried out online regardless of ERT. Additionally, when asked about the suitability of respective areas of language study for online learning, $49.5 \%$ of the students considered literature courses to be at least partially suitable, followed by linguistics (18.2\%), practical language (16.2\%) and methodology $(10.1 \%)$. The results reflect the standard nature of these areas. Reading assignments do not require interaction, whereas methodology often involves interaction-based tasks. Linguistics is commonly considered difficult by students and some of the respondents mentioned that linguistic issues require thorough in-class explanation and/ or discussion to be properly understood. Practical language lessons comprise communicative exercises that often involve multiple speakers, which is difficult to achieve in online spoken communication. Consequently, $37.4 \%$ of the students reported that, unless necessary, no area is suitable for the shift to online learning. ERT provided the students with more responsibility for their time management, which was received positively as time flexibility and the non-stop availability of online course material is considered to be one of the most appreciated advantages of online learning (e.g. Allen et al., 2019).

Regarding the student satisfaction with ERT, the collected answers indicate that one of the most important evaluation aspects was the lack of preparedness. Both the students and the instructors were forced to navigate uncharted territory and adapt to unprecedented circumstances. The teachers had to shift to a different mode of instruction at short notice, without firm guidelines or schedules available. The students recognised the difficulty of the situation and exhibited high tolerance and solidarity. This resulted in little to no expectations on the side of the students regarding the entire process, which in turn contributed to the assessment of ERT being overwhelmingly positive. Reynold and Chu (2020) argue that nobody could have been prepared for the (overnight) transition to ERT, which resulted in promptness of response to the situation becoming the major factor affecting satisfaction. Additionally, the students valued those modes of instruction that supplied experience similar or almost identical to standard teaching. This is inevitably tied to the external factors associated with the quarantine measures that brought a sudden change to even the most basic aspects of our lives. We believe that well-crafted ERT may have provided at least some form of what the students considered familiar and, therefore, possibly also comforting (cf. Sun, Tang and Zuo, 2020). According to our findings, more than $80 \%$ of the students missed the F2F interaction, which is in agreement with multiple other studies (e.g. Cole, Shelley and Swartz, 2014; Horzum, 2015; Graham, 2019) as online education lacks synchronicity by design. It follows that providing enough stimuli for recreation of F2F engagement leads to higher satisfaction. In addition to encouraging active participation in online spoken discussions, we should aim to utilise other methods of engagement in the online environment, e.g. forums, community hubs, social media, etc., that can contribute to the overall feeling of connectedness.

Next, we want to discuss the question of language skills development during ERT, as it is, after all, our primary area of focus. The majority of the students $(68.7 \%)$ reported no change to their skills, $24.2 \%$ improvement, and $7.1 \%$ deterioration. The "no-change" self-assessment can be attributed to the shortness of the ERT period; three months is a limited amount of time for any significant development to be recognized. Improvement is possibly caused by the increased exposure to the target language, which is considered more effective than guided learning (e.g. Krashen, 1988). Deterioration can be the result of the students not having the opportunity to use the language actively over the period of ERT. Nevertheless, the responses may not be an accurate representation of the real changes to the students' language skills as they remain a subjective assessment. We would also like to comment on the comparison of the responses of BA and MA students. Firstly, there is no significant difference in the evaluation of overall satisfaction. The reason for this is likely the tolerance and solidarity that has been discussed earlier, which does not seem to be related to the degree programme in any way. In regard to the stressfulness evaluation, the more experienced students (MA) were expected to report lower levels of stress. However, the chi-square test revealed that there is no (statistically) significant difference between BA and MA students in relation to stress. Lastly, a comparison was done for the three most frequently listed skills that the respondents believe to have acquired during ERT - namely technological skills, time management, and independence. While time management and independence were more or less evenly distributed between BA and MA students (less than 5\% deviation from the mean), technological skills showed a significant deviation of $13.4 \%$ for MA students. One reason might be the age difference; younger students are likely to be more tech-oriented in the increasingly digitalized world. Ultimately, it is important to note that our dataset is rather limited for providing conclusive answers related to differences in evaluation between BA and MA students, therefore, we refrain from making any generalizations.

Finally, based on the results of our investigation, we present the following hypotheses as areas for further research into the understanding of the student perception of online learning:

1. An abundance of asynchronous learning leads to higher levels of stress.

2. Regular provision of feedback correlates with student satisfaction. 
We recognize these phenomena as deserving of thorough measurement with the use of valid and reliable surveys.

\section{CONCLUSION}

The purpose of this paper has been to share the feedback we received from the students regarding the quality of ERT that took place over three months. The abruptness of the ERT pivot did not allow for much preparation prior to the shift to online teaching and we had to react to the situation - no matter how unprepared. However, there is already an abundance of theory and methodology dedicated to online education, which may, in retrospect, help us understand the entire process and provide the much necessary groundwork for future improvement. Together with the gathered feedback, we have had the chance to critically assess the ERT experience and learn what aspects and factors were considered efficient, but also inefficient.

We believe it is important to emphasize that prior to this emergency, our experience with online teaching was very limited. Fortunately, the whole situation was supported by a reciprocal wave of tolerance and solidarity. We are, nevertheless, aware of the fact that should a similar situation arise again in the future, the "grace period" is over and it is our responsibility to be adequately prepared, both as teachers and students. The positive feedback might serve as encouragement and also help us with the development of proper guidelines for another such emergency. What is more, some aspects of ERT can be integrated into standard teaching now that some of the possibilities have been collectively explored. After all, we live in an era of digitalization, and while certain aspects of education might not be suitable for online learning, adopting a hybrid approach is inevitable. We firmly believe that this experience should not be dismissed as a one-off incident. It should rather serve as a cathartic moment and, whether we are teachers or students, invite us to rethink our approach to education.

\section{REFERENCES}

Allen, M., Omori, K., Cole, A. W. and Burrell, N. (2019) 'Distance Learning and Student Satisfaction', In Moore, M. G. and Diehl, W. C. (eds.) Handbook of Distance Education, (pp. 122-132), 4th edition, New York and London: Routledge.

Ally, M. (2008) 'Foundations of Educational Theory for Online Learning', In Anderson, T. (ed.) The Theory and Practice of Online Learning, (pp. 15-44), 2nd edition, Edmonton: AU Press, Athabasca University.

Black. L. M. (2019) 'A History of Scholarship', In Moore, M. G. and Diehl, W. C. (eds.) Handbook of Distance Education, (pp. 3-18), 4th edition, New York and London: Routledge.

Bolliger, D. U. and Martindale, T. (2004) 'Key Factors for Determining Student Satisfaction in Online Courses', International Journal on E-Learning, Vol. 3, No. 1, pp. 61-67.

Bork, R. H. and Rucks-Ahidiana, Z. (2013) 'Role Ambiguity in Online Courses: An Analysis of Student and Instructor Expectations', CCRC Working Paper No. 64, New York: Community College Research Center, Columbia University. Available: https://ccrc. tc.columbia.edu/publications/role-ambiguity-in-online-courses. html [25 Aug 2020].

Bozkurt, A. and Sharma, R. C. (2020) 'Emergency Remote Teaching in a Time of Global Crisis Due to Corona Virus Pandemic', Asian Journal of Distance Education, Vol. 15, No. 1, pp. i-vi. https://doi. org/10.5281/zenodo.3778083

Buunk, A. P. and Gibbons, F. X. (2005) 'Social Comparison Orientation: A New Perspective on Those Who Do and Those Who Don't Compare with Others', In Guimond, S. (ed.) Social Comparison and Social Psychology: Understanding Cognition, Intergroup Relations and Culture, (pp. 15-32), Cambridge: Cambridge University Press.

Civitci, N. and Civitci, A. (2015) 'Social Comparison Orientation, Hardiness and Life Satisfaction in Undergraduate Students', Procedia - Social and Behavioral Sciences, Vol. 205, pp. 516-523. http://doi.org/10.1016/j.sbspro.2015.09.062

Cleveland-Innes, M., Garrison, R. D. and Vaughan, N. (2019) 'The Community of Inquiry Theoretical Framework', In Moore, M. G. and Diehl, W. C. (eds.) Handbook of Distance Education, (pp. 6778), 4th edition, New York and London: Routledge.
Cole, M. T., Shelley, D. J. and Swartz, L. B. (2014) 'Online Instruction, E-Learning, and Student Satisfaction: A Three Year Study', International Review of Research in Open and Distance Learning, Vol. 15, No. 6, pp. 111-131. http://doi.org/10.19173/ irrodl.v15i6.1748

Conrad, D. and Openo, J. (2018) Assessment Strategies for Online Learning: Engagement and Authenticity, Edmonton, AB: AU Press.

Eccles, J. S. and Wigfield, A. (2002) 'Motivational Beliefs, Values, and Goals', Annual Review of Psychology, Vol. 53, pp. 109-132.

Graham, C. R. (2019) 'Current Research in Blended Learning', In Moore, M. G. and Diehl, W. C. (eds.) Handbook of Distance Education, (pp.173-178), 4th edition, New York and London: Routledge.

Gross, K. (2020) 'Can Online Learning Be Trauma-Responsive?', New England Board of Higher Education, [Online], Available: https://nebhe.org/journal/can-online-learning-be-traumaresponsive [28 Aug 2020].

Hartnett, M. (2015) ‘Influences That Undermine Learners’ Perceptions of Autonomy, Competence and Relatedness in an Online Context', Australasian Journal of Educational Technology, Vol. 31, No. 1, pp. 86-99. https://doi.org/10.14742/ajet.1526

Hartnett, M. (2019) 'Motivation in Distance Education', In Moore, M. G. and Diehl, W. C. (eds.) Handbook of Distance Education, (pp. 145-157), 4th edition, New York and London: Routledge.

Harvard University (2020) Best Practices: Online Pedagogy, [Online], Available: https://teachremotely.harvard.edu/bestpractices [25 Aug 2020].

Heckel, C. and Ringeisen, T. (2019) 'Pride and Anxiety in Online Learning Environments: Achievement Emotions as Mediators Between Learners' Characteristics and Learning Outcomes', Journal of Computer Assisted Learning, Vol. 35, No. 5, pp. 667677. https://doi.org/10.1111/jcal.12367

Hidi, S. and Harackiewicz, J. M. (2000) 'Motivating the Academically Unmotivated: A Critical Issue for the 21st Century', Review of Educational Research, Vol. 70, No. 2, pp. 151-179. https://doi. org/10.3102/00346543070002151 
Hidi, S. and Renninger, K. A. (2006) 'The Four-Phase Model of Interest Development', Educational Psychologist, Vol. 41, No. 2, pp. 111-127. http://doi.org/10.1207/s15326985ep4102_4

Hodges, C. B., Moore, S., Lockee, B. B., Trust, T. and Bond, M. A. (2020) 'The Difference Between Emergency Remote Teaching and Online Learning', EDUCAUSE Review, [Online] Available: https://er.educause.edu/articles/2020/3/the-difference-betweenemergency-remote-teaching-and-online-learning [11 Sep 2020].

Horzum, M. B. (2015) 'Interaction, Structure, Social Presence, and Satisfaction in Online Learning', Eurasia Journal of Mathematics, Science \& Technology Education, Vol. 11, No. 3, pp. 505-512. https://doi.org/10.12973/eurasia.2014.1324a

Hurst, B., Wallace, R. and Nixon, S. B. (2013) 'The Impact of Social Interaction on Student Learning', Reading Horizons: A Journal of Literacy and Language Arts, Vol. 52, No. 4, pp. 375-398.

Jindrová, A., Vostrá Vydrová, H. and Dömeová, L. (2013) 'The Students' Evaluation of the E-Support in the Full Time Form of Study', Journal on Efficiency and Responsibility in Education and Science, Vol. 6, No. 2, pp. 119-133. https://doi.org/10.7160/ eriesj.2013.060205

Koller, D. (2012) 'What We're Learning From Online Education', [Video file], TED, Available: https://www.ted.com/talks/daphne koller what we re learning from online education/transcript [14 Jul 2020].

Korpi, S. (2019) 'Portfolio Project as Summative Language Assessment: Engaging Learners Online', International Journal of E-Learning \& Distance Education, Vol. 34, No. 2, pp. 1-18.

Krashen, S. D. (1988) Second Language Acquisition and Second Language Learning, London: Prentice Hall International.

Kuo, Y.-C., Walker, A., Belland, B. R. and Schroder, K. E. E. (2013) 'A Predictive Study of Student Satisfaction in Online Education Programs', The International Review of Research in Open and Distributed Learning, Vol. 14, No. 1, pp. 16-39. https://doi. org/10.19173/irrodl.v14i1.1338

Lehman, R. M. and Conceição, S. C. O. (2010) Creating a Sense of Presence in Online Teaching, San Francisco: Jossey-Bass.

Leonnard (2019) 'Exploring the Relationship Among E-Service Quality, E-Trust, E-Satisfaction and Loyalty at Higher Education Institutions', Journal on Efficiency and Responsibility in Education and Science, Vol. 12, No. 4, pp. 103-110. https://doi. org/10.7160/eriesj.2019.120401

Martin, F., Wang, C. and Sadaf, A. (2018) 'Student Perception of Helpfulness of Facilitation Strategies That Enhance Instructor Presence, Connectedness, Engagement and Learning in Online Courses', The Internet and Higher Education, Vol. 37, pp. 52-56. https://doi.org/10.1016/j.iheduc.2018.01.003

Moore, G. M. (2019) 'The Theory of Transactional Distance', In Moore, M. G. and Diehl, W. C. (eds.) Handbook of Distance Education, (pp. 32-46), 4th edition, New York and London: Routledge.

Muilenburg, L. Y. and Berge, Z. L. (2005) 'Student Barriers to Online Learning: A Factor Analytic Study', Distance Education, Vol. 26, No. 1, pp. 29-48. http://doi.org/10.1080/01587910500081269

MŠMT ČR (2020) Doporučení pro zajištění výuky distanční formou v době omezení činnosti vysokých škol, [Online], Available: https:// www.msmt.cz/vzdelavani/vysoke-skolstvi/doporuceni-prozajisteni-vyuky-distancni-formou-v-dobe?lang=1 [3 Aug 2020].

Newman, T. and Beetham, H. (2017) 'Student Digital Experience Tracker 2017: The Voice of 22,000 UK Learners', Jics, [Online], Available at: http://repository.jisc.ac.uk/6662/1/ Jiscdigitalstudenttracker2017.pdf [28 Aug 2020].
Parkes, M., Reading, C. and Stein, S. (2015) 'Student Preparedness for University E-Learning Environments', The Internet and Higher Education, Vol. 25, No. 4, pp. 1-10. https://doi.org/10.1016/j. iheduc.2014.10.002

Ramsden, P. (2003) Learning to Teach in Higher Education, 2nd edition, New York: Routledge Falmer.

Reynolds, R. and Chu, S. K. W. (2020) 'Guest Editorial', Information and Learning Sciences, Vol. 121, No. 5/6, pp. 233-239. https:// doi.org/10.1108/ILS-05-2020-144

Ryan, R. M. and Deci, E. L. (2017) Self-Determination Theory: Basic Psychological Needs in Motivation, Development, and Wellness, New York and London: The Guilford Press.

Quintana, R. and Quintana, C. (2020) 'When Classroom Interactions Have to Go Online: The Move to Specifications Grading in a Project-Based Design Course', Information and Learning Sciences, Vol. 121, No. 7/8, pp. 525-532. https://doi.org/10.1108/ ILS-04-2020-0119

Saadé, R. G. and Kira, D. (2009) 'Computer Anxiety in E-Learning: The Effect of Computer Self-Efficacy', Journal of Information Technology Education, Vol. 8, pp. 177-191. https://doi. org/10.28945/166

Saadé, R. G., Kira, D., Mak, T. and Nebebe, F. (2017) 'Anxiety and Performance in Online Learning', Proceedings of the Informing Science and Information Technology Education Conference, Vietnam, pp. 147-157. Santa Rosa, CA: Informing Science Institute. Available: http://www.informingscience.org/ Publications/3736 [25 Aug 2020].

Shapiro, H. B., Lee, C. H., Wyman Roth, N. E., Li, K., ÇetinkayaRundel, M. and Canelas, D. A. (2017) 'Understanding the Massive Open Online Course (MOOC) Student Experience: An Examination of Attitudes, Motivations, and Barriers', Computers \& Education, Vol. 110, pp. 35-50. https://doi.org/10.1016/j. compedu.2017.03.003

Sheridan, K. and Kelly, M. A. (2010) 'The Indicators of Instructor Presence That Are Important to Students in Online Courses', Journal of Online Learning and Teaching, Vol. 6, No. 4.

Schiefele, U. (1991) 'Interest, Learning, and Motivation', Educational Psychologist, Vol. 26, No. 3/4, pp. 299-323. https://doi.org/10.10 $\underline{80 / 00461520.1991 .9653136}$

Schiefele, U. (1999) 'Interest and Learning from Text', Scientific Studies of Reading, Vol. 3, No. 3, pp. 257-279. https://doi. org/10.1207/s1532799xssr0303_4

Schunk, D. H. (1989) 'Self-Efficacy and Achievement Behaviors', Educational Psychology Review, Vol. 1, No. 3, pp. 173-208.

Stavredes, T. M. and Herder, T. M. (2019) 'Instructional Strategies to Support Student Persistence', In Moore, M. G. and Diehl, W. C. (eds.) Handbook of Distance Education, (pp. 133-144), 4th edition, New York and London: Routledge.

Stufflebeam, D. and Zhang, G. (2017) The CIPP Evaluation Model, New York: Guilford Publications.

Sun, P.-C., Tsai, R. J., Finger, G., Chen, Y.-Y. and Yeh, D. (2008) 'What Drives a Successful E-Learning? An Empirical Investigation of the Critical Factors Influencing Learner Satisfaction', Computers \& Education, Vol. 50, No. 4, pp. 1183-1220. https://doi. org/10.1016/j.compedu.2006.11.007

Sun, S. Y. H. (2011) 'Online Language Teaching: The Pedagogical Challenges', Knowledge Management \& E-Learning: An International Journal, Vol. 3, No. 3, pp. 428 - 447.

Sun, S. Y. H. (2014) 'Learner Perspectives on Fully Online Language Learning', Distance Education, Vol. 35, No. 1, pp. 18-42. http:// doi.org/10.1080/01587919.2014.891428 
Sun, L., Tang, Y. and Zuo, W. (2020) 'Coronavirus Pushes Education Online', Nature Materials, Vol. 19, No. 6, p. 687. https://doi. org/10.1038/s41563-020-0678-8

Vanslambrouck, S., Zhu, C., Lombaerts, K., Philipsen, B. and Tondeur, J. (2018) 'Students' Motivation and Subjective Task Value of Participating in Online and Blended Learning Environments', The Internet and Higher Education, Vol. 36, pp. 33-40. https:// doi.org/10.1016/j.iheduc.2017.09.002

Vayre, E. and Vonthron, A.-M. (2019) 'Relational and Psychological Factors Affecting Exam Participation and Student Achievement in Online College Courses', The Internet and Higher Education, Vol.43, 100671. https://doi.org/10.1016/j.iheduc.2018.07.001

OnlineSchools.org (2020) The History of Online Schooling, [Online], Available: https://www.onlineschools.org/visual-academy/thehistory-of-online-schooling/ [15 Sep 2020].

Wentzel, K. R. and Brophy, J. E. (2014) Motivating Students to Learn, New York \& London: Routledge.
White, J. B., Langer, E. J., Yariv, L. and Welch IV, J. C. (2006) 'Frequent Social Comparisons and Destructive Emotions and Behaviors: The Dark Side of Social Comparisons', Journal of Adult Development, Vol. 13, No. 1, pp. 36-44. http://doi.org/10.1007/s10804-006-9005-0

Whittle, C., Tiwari, S., Yan, S. and Williams, J. (2020) 'Emergency Remote Teaching Environment: A Conceptual Framework for Responsive Online Teaching in Crises', Information and Learning Sciences, Vol. 121, No. 5/6, pp. 311-319. https://doi.org/10.1108/ ILS-04-2020-0099

Wombacher, K.A., Harris, C. H., Buckner, M. M., Frisby, B. and Limperos, A. M. (2017) 'The Effects of Computer-Mediated Communication Anxiety on Student Perceptions of Instructor Behaviors, Perceived Learning, and Quiz Performance', Communication Education, Vol. 66, No. 3, pp. 299-312. https://doi.org/10.1080/03634523.2016.12 $\underline{21511}$

Zimmerman, B. J. (2000) 'Self-Efficacy: An Essential Motive to Learn', Contemporary Educational Psychology, Vol. 25, No. 1, pp. 82-91. https://doi.org/10.1006/ceps.1999.1016 